Fanum

Sociológico

\section{Forum Sociológico}

Série II

$22 \mid 2012$

Saúde e multiculturalidade

\title{
Outros corpos: imigração, saúde e etnopolíticas da cidadania
}

\section{Chiara Pussetti e Vitor Barros}

\section{(2) OpenEdition \\ 1 Journals}

Edição electrónica

URL: https://journals.openedition.org/sociologico/691

DOI: 10.4000/sociologico.691

ISSN: 2182-7427

Editora

CICS.NOVA - Centro Interdisciplinar de Ciências Sociais da Universidade Nova de Lisboa

\section{Edição impressa}

Paginação: 23-31

ISSN: 0872-8380

\section{Refêrencia eletrónica}

Chiara Pussetti e Vitor Barros, "Outros corpos: imigração, saúde e etnopolíticas da cidadania», Forum Sociológico [Online], 22 | 2012, posto online no dia 26 fevereiro 2013, consultado o 31 março 2022.

URL: http://journals.openedition.org/sociologico/691 ; DOI: https://doi.org/10.4000/sociologico.691

Este documento foi criado de forma automática no dia 31 março 2022.

(C) CICS.NOVA 


\title{
Outros corpos: imigração, saúde e etnopolíticas da cidadania
}

\author{
Chiara Pussetti e Vitor Barros
}

1 No recente contexto da União Europeia os assuntos relacionados com a migração tomaram uma importância capital para a atividade governamental, fazendo emergir a necessidade de estudar, categorizar e monitorizar as populações migrantes e a sua integração. Embora uma parte substantiva da produção nas ciências sociais se tenha concentrado precisamente nas resistências e dificuldades da integração dos imigrantes em estruturas sociais preexistentes (processos de discriminação, controle, punição e exclusão), já o complexo dispositivo assistencialista que se construiu em torno dos imigrantes é frequentemente alvo de menos interesse. E no entanto, nas últimas décadas, disponibilizaram-se importantes estruturas de financiamento e mobilizaramse os mais diversos agentes e campos de expertise no sentido de criar e expandir uma rede de cuidados sociais responsável pela intervenção junto de populações desfavorecidas com exclusiva ou elevada incidência de imigrantes. Na verdade, poderíamos dizer que mais que a monitorização de integração dos imigrantes, o principal campo de problematização governamental tem sido as condições de vida excedente (Cowen e Shenton, 1996; Duffield, 2007) do culturalmente outro, tendo-se realizado impressionantes esforços aos níveis nacional e transnacional no desenvolvimento de políticas e implementação de variadíssimos programas que provocaram tensões sociais, fissuras políticas e questionamento constante sobre o papel do Estado e os estatutos de cidadania.

O nosso objectivo, neste artigo, é indagar a forma particular como os programas de intervenção junto destas populações tentam gerir uma tensão que se expressa numa dicotomia vulnerabilidade/risco, que por sua vez se expressa numa outra dicotomia assistência/segurança. Mesmo quando tal não é claramente formulado, devido às suas assunções de base, os sectores de apoio social têm visado cada vez mais as populações migrantes, entrando, por exemplo, nos bairros sociais através de projetos de proximidade às comunidades. Programas que têm tido a particularidade, nos últimos tempos, de ir além de aliviar as condições de pobreza destas populações: eles 
desenvolvem atividades que intervêm profundamente na organização do seu quotidiano, orientando o seu comportamento, corpos, moralidade e estilos de vida.

O interesse último da nossa pesquisa é portanto olhar para a contradição aparente entre os objetivos de proteção e correção evidentes nestes programas e políticas sociais, questionando as formas de problematização - da configuração histórica de um dado objeto de intervenção aos projetos elaborados com um determinado fim em vista - e os campos de ação - instituições, atores, saberes, instrumentos - a partir dos quais se promove a gestão, a monitorização e a orientação das características físicas, mentais, comportamentais, ou morais de determinadas populações ${ }^{1}$. Olhando para este tipo particular de "tecnologias de cidadania" (Inda, 2006) no Portugal contemporâneo, prestaremos especial atenção, por um lado, aos processos pelos quais certos modos de vida dos imigrantes têm sido considerados particularmente problemáticos, prestando atenção principalmente à trajetória que liga a orientação das políticas públicas ao desenvolvimento das instituições e práticas de apoio social, à forma como os migrantes articulam estas normas com as suas próprias estratégias de vida.

Para os objetivos deste artigo, apresentaremos alguns exemplos centrados na relação entre profissionais dos serviços sociais e os seus utentes imigrantes, segundo uma metodologia do que se poderia chamar uma etnografia de interface. Aqui o objeto último de estudo não são políticas públicas, instituições de solidariedade, ou pessoas em situação de pobreza, como se constituíssem diferentes níveis de análise do macro ao micro, mas sim a análise da própria constituição de um campo de problematização e intervenção sobre a conduta humana, que não pode ser concebida ou praticada fora dessa mesma configuração. Estudar a interface não é portanto estudar a graduação qualitativa da intervenção ou da experiência de uma pobreza preexistente, mas sim estudar a relação entre os diferentes elementos que estão presentes na emergência de um campo chamado pobreza - no caso, a pobreza ligada à circulação da vida migrante excedente - no qual e perante o qual tanto as instituições como a ação humana se passam a definir.

\section{Dependência e responsabilidade: o trabalho da compaixão}

5 Os desenvolvimentos da economia portuguesa dos últimos anos, enquadrados num contexto de crise económica global, espoletaram as habituais medidas de contenção na despesa pública, mas também a habitual preocupação por aqueles já em condições desfavorecidas que sofreriam mais com os cortes nos benefícios sociais. 0 novo governo que tomou posse a 21 de Junho de 2011 anunciou a 5 de Agosto na voz de Pedro Mota Soares, ministro da Solidariedade e Segurança Social, um novo Programa de Emergência Social, num discurso com três importantes argumentos implícitos. 0 primeiro prende-se com o debate que opõe a dependência à capacitação dos indivíduos no sistema de welfare: "vamos investir nas pessoas"; "não queremos que as prestações sociais se transformem numa forma de assistência permanente"; "como diz o provérbio chinês, nuns casos damos o peixe, nos outros ensinamos a pescar". O segundo diz respeito ao descontentamento social que opõe o valor do trabalho à fraude do sistema: "a sociedade portuguesa quer garantir a todos uma oportunidade baseada no valor do trabalho e não quer que o dinheiro dos seus impostos seja permeável à fraude e ao abuso". o terceiro salienta o debate em torno do papel do Estado que discute a promoção de uma rede social baseada no 
Estado por oposição à privatização do sector de assistência social: "É um programa que não quer dizer mais Estado, mas mais instituições sociais e melhor política social. Uma rede de solidariedade social conta com todos. Contamos com a proximidade e a experiência das instituições sociais no terreno."

Estes debates não têm evidentemente nada de original nas idiossincrasias da atualidade portuguesa. A tendência da reconfiguração da rede de cuidados sociais anda intimamente ligada a mudanças paradigmáticas extremamente relevantes nas últimas décadas, onde o Estado tem desempenhado um papel cada vez mais complexo, e onde o contexto americano surge inevitavelmente como o vocativo mais determinante a nível internacional. Da variadíssima série de razões que tornaram famosa a presidência de Bill Clinton, uma delas foi seguramente a de ter feito passar o Personal Responsibility and Work Opportunity Act (PRWORA) em 1996, que ficaria conhecido por Welfare Act, que iria, nas suas próprias palavras, "end welfare as we know it". 0 objectivo era eliminar a dependência do sistema assistencialista, capacitando as pessoas para serem autossuficientes, autónomas, responsáveis e membros produtivos da sociedade. A importância da lei, que, de resto, seria vista por muitos sectores como o restaurar da "ética americana do trabalho", enquadra-se num longo debate sobre a dependência do assistencialismo que pairava há várias décadas na sociedade americana. $\mathrm{O}$ mito da welfare queen, a mãe solteira negra conduzindo um Cadillac que defraudava impunemente o sistema de benefícios sociais, usado exaustivamente por Ronald Reagan na sua famosa campanha presidencial de 1976, tornou-se não apenas parte do folclore americano - na verdade, também do europeu - como se tornou também um substituto de duas questões sociais particularmente complexas.

7 Em primeiro lugar reconfigurou em termos atuais a pobreza como um dos problemas quintessenciais das sociedades modernas onde, em termos gerais, os sujeitos constituintes de população excedente sempre foram a antítese do sujeito liberal. Por um lado, descreveu a constituição de uma classe de sujeitos dependentes sem dignidade nem autonomia, que não eram capazes ou não desejavam ser autossuficientes e tomar conta de si mesmos. Por outro lado, relacionou os beneficiários do sistema com sujeitos desprovidos de carácter moral e, por extensão, construiu a ideia do sistema de apoio social como uma cobertura para a apatia, preguiça e decadência moral.

8 Em segundo lugar, com a associação direta às populações migrantes, ajudou a reclassificar a pobreza de um problema essencialmente de natureza classista de desigualdade socioeconómica e má distribuição de rendimentos em direção a um problema inerentemente racializado de desvio comportamental, deficiências morais e patologia cultural.

Esta nova racionalidade de tom cultural na preocupação de governar uma população para a qual as ciências sociais (e a Antropologia e a Sociologia em particular) deram um importante contributo - tornou-se um substituto parcial mas particularmente eficiente para o racismo biologicamente determinado de tempos coloniais. De facto, emerge do próprio processo de descolonização, quando uma migração em massa inverte o fluxo tradicional norte-sul e muda radicalmente a configuração da relação entre comunidades nacionais, circulação de população excedente e segurança internacional num novo tabuleiro político de estados igualmente legítimos e independentes (Duffield, 2007). A circulação da diferença cultural tornou-se não apenas uma questão de segurança, como promoveu também um dos mais impressionantes mecanismos de agentes e instituições do período pós-guerra: o desenvolvimento. 
10 A expansão da ideia liberal de aperfeiçoar e melhorar os contextos políticos - por definição subdesenvolvidos, como a designação atual de estados falhados, por exemplo, continua a demonstrar -, de onde um número incontável de migrantes legais e ilegais, não-cidadãos e refugiados estavam a fugir, revestiu-se de uma importância fundamental. Agir a vários níveis, desde as crises de fome, as epidemias crónicas, a pobreza, a instituições políticas frágeis, às perceções culturais do corpo e da vida que não respeitam o sentido liberal dos direitos e da liberdade, era atacar ao mesmo tempo uma ameaça às coesões nacionais e à segurança internacional.

11 Os pressupostos liberais de intervenção sobre as condições de vida do "outro" continuaram até ao presente. Num famoso discurso sobre a "guerra à pobreza", George W. Bush declarava em $2002^{2}$ como necessariamente as ações ligadas à ajuda para o desenvolvimento têm de estar conectadas com reformas jurídicas, políticas e económicas, e como, insistindo na reforma, estaremos fazendo o trabalho da compaixão. De acordo com o seu discurso, homens e mulheres são naturalmente feitos para a liberdade económica e política; são agentes que, se lhes for dada a oportunidade, se forem ajudados, desenvolverão o seu espírito de iniciativa, serão agentes economicamente racionais, terão melhor educação, serão livres e a prosperidade virá com o triunfo da liberdade. Ficando do lado da liberdade e do bom governo, libertaremos milhões de pessoas da prisão da pobreza.

12 Estes sujeitos são construídos como vulneráveis, mas também como um risco: faltamlhes as competências necessárias para exercerem a sua liberdade, mas também lhes faltam os traços morais e psicológicos centrais à performance da cidadania liberal, como a autossuficiência, a autonomia ou até o controle das paixões ou impulsos sexuais. Dizem-nos portanto que devemos agir a dois níveis: um que é estrutural, onde o objetivo é criar as instituições certas, promover a sociedade civil, remover os obstáculos políticos e económicos ao desenvolvimento; e um que é pedagógico, onde o objetivo é educar, cultivar as competências do indivíduo, promovendo uma transformação moral e pessoal em direção a um self autónomo e liberal.

13 A primeira dimensão da nossa problematização é portanto esta atenção obsessiva com as populações desfavorecidas - e em particular as populações oriundas de contextos subdesenvolvidos -, que continua até aos nossos dias, esta mentalidade que sustenta a constituição de um domínio de intervenção sobre aqueles que, supostamente, não conseguem cuidar de si próprios. Mais ainda, é necessário indagar como é que este problema se torna inextrincável da retórica que constitui estas intervenções como um imperativo humanitário, uma base da civilização, uma conquista do progresso da humanidade - porque o princípio retórico que lhes subjaz continua a sustentar que fazer estas reformas é fazer o trabalho da compaixão. Como vimos, estas intervenções têm-se centrado no bem moral de ajudar os outros, mas também com os riscos associados a populações vistas como vulneráveis, ao mesmo tempo em risco, e constituindo um risco.

14 A segunda dimensão da nossa problematização é a particularidade de que este intervencionismo pós-Segunda Guerra Mundial sobre a pobreza é, desde a sua origem, inerentemente racializado, radicado na passagem de uma preocupação colonial com "tipos biológicos num lugar" para uma preocupação contemporânea com "tipos culturais a circular", simbólica e politicamente projetados nos imigrantes, a corporificação da diferença cultural em movimento (Duffield, 2007). A política do assistencialismo é portanto, iminentemente, uma etnopolítica de cidadania. Mais uma 
vez, tal não significa que a racionalidade de intervenção sobre a pobreza seja racista, mas sim racializada; tal como não é de natureza neocolonial, mas sim, literalmente, pós-colonial. o que podemos ver que foi perpetuado, outrossim, é a divisão de grupos humanos de acordo com a falta de traços ou disposições biopsicológicos, culturais ou morais, que necessitam de ser tratados com educação e orientação, justificando uma forma de tutela liberal (Cowen e Shenton, 1996; Mehta, 1999) sobre essas populações.

\section{A ditadura da benevolência: educar, disciplinar, corrigir}

Para analisar as relações entre o sector da assistência social, a expertise médica e o governo dos corpos, começámos a acompanhar alguns projetos portugueses de intervenção social e realizámos entrevistas com profissionais destes mesmos projetos. Em todos os projetos - que desejam educar e apoiar os cidadãos necessitados sublinha-se explicitamente a preocupação e as dificuldades que tentam enfrentar através da intervenção nos bairros sociais. Uma psicóloga, chefe de um projeto de intervenção social num bairro periférico de Lisboa, identifica assim o problema que a sua organização tenta resolver:

Um dos traços comuns de uma grande parte desta população pobre é a sua vulnerabilidade física, psíquica e social: a perigosa fragilidade que os torna seres passivos e dependentes. A intervenção socioeducativa visa recolocar estas pessoas na sociedade, fortalecendo a sua autonomia através da sua capacitação, que irá conduzir à sua emancipação. Tentamos ajudar os imigrantes a aprender a autodisciplina. Temos de ensiná-los a gerirem-se melhor, a utilizarem as suas casas de forma conveniente e adequada, a cuidarem de si e dos seus filhos com dignidade.

Uma assistente social de um projeto de educação e prevenção no âmbito da saúde identifica com estas palavras as dificuldades principais dos seus utentes:

Para eles se tornarem cidadãos portugueses devem adquirir as nossas regras: higiene, competência e responsabilidade em relação à saúde e ao cuidado pessoal e familiar são um requisito fundamental. Promover uma responsabilização individual e social significa criar hábitos saudáveis, uma ética do trabalho, características indispensáveis para tornar estas pessoas independentes.

Salienta outro técnico de reinserção social:

Mudar mentalidades é difícil e é preciso obrigá-los a vir, senão não fazem.

18 A premissa de partida aqui, porquanto implícita, é que estas pessoas não têm a competência necessária para gerir as suas próprias vidas. Embora possam reconhecer o que é do seu próprio interesse, não têm a disciplina necessária para tornar o comportamento compatível com a intenção. As suas vidas são desordenadas ao ponto de nenhuma oportunidade ou incentivo, porquanto claros, poder induzi-los a agir no seu próprio interesse. Neste contexto, então, a assistência social deve agir como uma autoridade de supervisão e disciplina, para o próprio bem dos utentes, que "precisam de ser ensinados a viver de forma construtiva". Ao adotar essa postura, o sector de assistência convida os assistentes sociais a atuar como figuras de autoridade, além de como figuras de suporte. A aproximação metafórica do imigrante com a criança, que precisa de ser educada, disciplinada e conduzida de mão dada na direção certa, está presente na maior parte das entrevistas que realizámos. Reportamos duas, a título de exemplo, para ilustrar este tipo de racionalidade. Coordenadora de um projeto de intervenção social: 
Na nossa opinião, estes indivíduos vulneráveis não sabem gerir as opções que têm à disposição, não sabem como escolher o caminho certo, e portanto vamos-lhe dar uma mão, como se faz para ajudar as crianças, andar juntos de mãos dadas. Esta é a melhor definição de vulnerabilidade: são pessoas pobres, carentes de responsabilidade, educação, iniciativa, e portanto precisam de apoio, como as crianças. Temos de lhe dar uma direção, dizer claramente por aqui sim, por aí não: ainda não chegámos ao ponto em que estas pessoas estão prontas para caminhar sozinhas.

E reforça o perito independente do PNAI:

Este pessoal, se não tiver umas pessoas no local a ensinar, não vai aprender. Se o gado não tiver pastor sente-se abandonado. Ao acabarem os projetos, as pessoas ficam desamparadas. É como uma mãe que abandona o filho sem o encaminhar, sem lhe abrir caminho e dizer para seguir por ali. Pode dizer onde ir, mas se não lhe der a mão ele não vai lá, tem medo de avançar. Para que esta gente realmente faça algo, é preciso empurrar. Empurrar significa que é preciso obrigar um bocadinho, porque as pessoas não vão lá. Portanto, tem de ser assim, tem de ser dando informação às pessoas e obrigando.

20 Como crianças, nessa visão, as pessoas vulneráveis não têm a capacidade de saber o que é do seu próprio interesse, e ainda menos de desenvolver a autodisciplina necessária para agir eficazmente na base destes conhecimentos. Como os adultos, os profissionais da assistência social estão na posição certa para compreender de facto qual é o interesse dos outros. Além disso, os adultos têm a obrigação moral de usar a sua autoridade para dirigir e supervisionar as crianças de forma a ajudá-las a crescer. Para o próprio bem da criança, eles devem dizer não de vez em quando para limitar a criança, devem-se impor quando a criança opõe resistência, e devem punir a criança quando é necessário, para corrigir o seu comportamento.

21 O desafio é transformar os cidadãos carenciados de recetores passivos de assistência em indivíduos ativos e autónomos: para este efeito, existem formas de reinserir os excluídos em circuitos de autogestão responsável, para os reconstituir ativando as suas capacidades de cidadania autónoma. O governo dos margens, por outras palavras, não é tanto um mecanismo de controle social, mas mais um espaço de criação de cidadania. A luta à marginalidade é uma espécie de trabalho de transformação moral, enquanto procura estabelecer virtudes cívicas e cultivar bons hábitos e disposições mentais, e condutas corretas. Portanto, autossuficiência e integração no trabalho, respeito, obediência e autodisciplina como membro da comunidade são considerados como não apenas um bem moral, mas como um pré-requisito para a cidadania: condições prévias para ter as bases morais de um bom membro da sociedade que portanto merece respeito e direitos iguais, e que pode ser considerado competente para participar na vida cívica.

\section{Patologias sociais: prevenir e curar}

O sector de assistência social não tenciona simplesmente impor decisões aos pobres, mas curar melhor as patologias mais profundas da dependência e da desordem - para os transformar em sujeitos capazes de regular o seu comportamento em maneiras novas e mais adequadas. Apesar de existirem diferentes técnicas de intervenção social que partilham o objetivo de conduzir os marginais na direção de uma cidadania responsável, decidimos aqui abordar somente um dos âmbitos da nossa pesquisa, o da saúde, apresentando alguns dados preliminares que podem exemplificar como esta 
forma de cuidar dos imigrantes orientando a sua conduta se inscreve de forma profunda na vida das pessoas. O campo de intervenção médica, na verdade, tem um papel central na despolitização do governo da vida e da morte, da saúde e da doença, na tentativa de levar as pessoas a ter hábitos saudáveis, a reduzir riscos, a ter certas conceções normalizadas do seu corpo, na pedagogia, enfim, daquilo que medicamente é considerado um corpo saudável.

Consideremos que as pessoas que solicitam subsídios sociais do Estado são aconselhadas (muitas vezes obrigadas, como condição para receber o subsídio) a frequentar ateliers destinados a implementar as suas capacidades e a orientar o seu próprio projeto de vida. Analisámos, portanto, alguns cursos destinados à implementação de uma parentalidade positiva através de ações específicas de aconselhamento, educação e treino parental, destinadas a promover responsabilidade, a melhorar as competências com os filhos e a prevenir a reincidência de gravidez.

Pelas palavras de uma técnica de desenvolvimento comunitário:

Temos os imigrantes africanos com uma questão cultural muito grande, que é: temos famílias monoparentais, mães sozinhas com 3, 4, 5 filhos. Para o homem africano usar preservativo, quando eu introduzo isso a falar com elas, a explicar que é importante, que é por causa das doenças, elas aquilo que me dizem é que eles não aceitam, não querem, não usam. Também acredito que os africanos, a nível de sexualidade, têm as coisas um bocadinho mais à flor da pele. Mas em África é a comunidade que cria, eles vão tendo os filhos e a própria comunidade os cria. Aqui em Portugal continuam a reproduzir esse comportamento, criando os filhos com os nossos subsídios. Como não conseguem perceber a prevenção, é melhor usar então métodos mais drásticos.

O papel do técnico de saúde ou do profissional do serviço social - intermediários entre o Estado e os futuros cidadãos - na orientação dos imigrantes na direção das normas ocidentais é crucial. Legitimados pela autoridade e a objetividade do conhecimento científico, peritos em prevenção e saúde, em todas as entrevistas os profissionais sustentam saber o que é certo para os utentes, muito melhor do que os próprios. Este tipo de relação é evidente quando se analisam os dados resultantes das entrevistas realizadas durante o trabalho de campo.

Lúcia, mulher cabo-verdiana de 28 anos com 3 filhos:

O médico sugeriu que eu laqueasse as trompas porque não tenho capacidade de sustentar mais filhos. A assistente social perguntou-me: tens a certeza? Só tens 28 anos podes querer ter mais filhos e a laqueação é irreversível. Sim, eu sei mas o médico diz que não tenho condições para criar mais filhos.

Karen, guineense, 26 anos, 3 filhos:

Quando fui à consulta, a médica disse que a melhor coisa a fazer era a laqueação de trompas. Falaram que era a solução certa para cuidar melhor dos filhos que já tinha e não apanhar mais gravidezes. Eu sabia que a minha prima e outras amigas já tinham feito, então como já tinha os meus filhos, eu decidi fazer.

Confirma uma das técnicas de saúde:

Há muitas meninas irresponsáveis: não fazem um planeamento familiar e, quando ficam grávidas, a única coisa a que recorrem é ao aborto. Ou há outras, que têm filhos um atrás do outro. (...) Em casos extremos há médicos que até sugerem a laqueação das trompas, mas a precaução que nós costumamos tomar é a colocação do implante anticoncecional subcutâneo, no braço das meninas que vêm para qualquer tipo de questão de saúde. É uma forma de prevenção fácil e eficaz, 
considerando que há muitas meninas que se não sabem disciplinar em relação ao planeamento familiar. contracetivos tem ligações com a naturalidade da mulher, sendo que as mulheres africanas ou brasileiras usam muito mais do que as portuguesas ${ }^{3}$. Um estudo comissionado pelo ACIDI (Dias et al., 2009) para a implementação de novas políticas de intervenção na saúde reprodutiva das mulheres imigrantes indica que estas mulheres tendem a ter numerosas gravidezes por não utilizarem qualquer método contracetivo e não terem conhecimento adequado sobre os vários métodos de contraceção. Neste estudo é dito que em muitos casos, para contornar os limites devidos a falta de educação, elevado desconhecimento dos métodos contracetivos, a constrangimentos sociais, assim como a crenças e valores culturais sobre a fertilidade e a sexualidade geradores de conflitos pessoais, de forma geral foi sugerido o incentivo de métodos alternativos: no estudo reporta-se casos de aconselhamento de laqueação de trompas.

As nossas entrevistas realçam que a iniciativa mais divulgada foi a disponibilização gratuita do implante contracetivo subcutâneo para todas as mulheres em idade fértil, sendo um método que evita a gravidez durante um período de até três anos que não tem a complexidade do manejo da pílula ("que, com estas mulheres, ora é esquecida e ora tomada incorretamente") ou a dificuldade de negociação do uso de preservativo com os parceiros. Os implantes hormonais são apresentados pelos profissionais da saúde como um dos mais práticos e eficazes métodos de prevenção à gravidez. Uma das técnicas de saúde de um projeto de intervenção prática e sensibilização sobre a temática da saúde e imigração afirma que o Implanon, sendo uma nova tecnologia, seria um medicamento de alto custo no mercado e portanto de acesso restrito, principalmente para grupos com baixos rendimentos. Distribuir gratuitamente o implante significa ultrapassar as "barreiras sociais" e as "limitações culturais" e garantir uma forma infalível de controlo dos nascimentos. Na lógica de delimitação do público-alvo desta intervenção - continua a informante -, as mulheres que mais precisam são as consideradas de risco:

As com maiores possibilidades de reincidência de gravidez por conta de fatores sociais, culturais e psicológicos; as que já têm filhos e vivem de subsídios; as mulheres mais promíscuas, que não se percebe bem de quem têm filhos; as que têm famílias desestruturadas e que não cuidam com a devida atenção dos filhos que já têm.

Como já falava Howard Becker em 1963, é interessante lembrar a importância do olhar do outro para a definição das categorias (vulneráveis/em risco) e dos comportamentos considerados como desviantes. Neste sentido o processo pelo qual estas mulheres são classificadas como grupo de risco implica uma categorização construída socialmente a partir de valores morais hegemónicos e dos interesses das pessoas que estão no poder de imputar este rótulo. A mesma categoria de risco é aqui interessante, porque não indica necessariamente um desvio da regra, mas sim um possível desvio. Neste sentido o Implanon é um fármaco preventivo, aliás o mais eficaz e efetivo, para reduzir riscos e prevenir danos (gravidezes numa idade ou condição familiar inadequadas) ou desvio (fraude e welfare queen).

Pelas palavras de outra técnica, psicóloga, responsável de atividades de formação: famílias com o pai são pouquíssimas. A diferença é como é visto o conceito de família monoparental: para a comunidade afrodescendente, não é visto como um 
problema e continuam assim, entre gravidezes subsequentes e subsídios, abonos e RSI.

Contra a questão da dependência de subsídios, ou a dúvida de manipulação das mães que - segundo a opinião das assistentes sociais entrevistadas - preferem fazer mais filhos para ter abonos, o emprego do Implanon é apresentado como a solução mais eficaz e atual ao nível de prevenção. Segundo muitas das técnicas entrevistadas: o implante é uma arma eficaz para combater a gravidez adolescente, assim como para limitar o excesso de crianças nas familias que depois não têm condições para cuidar delas como deveriam.

Como a maior parte das mulheres imigrantes são bastante resistentes à ideia do planeamento familiar, este tipo de intervenção, baseada no controle da natalidade, torna-se aparentemente uma boa estratégia para evitar os múltiplos riscos subsequentes. Entre estes, a Alta Comissária da Saúde, Maria do Céu Machado, relata com preocupação o problema da prematuridade e do baixo peso à nascença das crianças de mulheres de origem africana, por razões sociais e até por razões genéticas. Este problema contribui aparentemente para transmitir uma imagem negativa do país a nível internacional ${ }^{4}$. O incentivo ao emprego do implante subcutâneo também serve para prevenir práticas correntes nas comunidades imigrantes para a interrupção da gravidez como forma de controle da natalidade, sustenta uma enfermeira de um projeto de saúde materno-infantil que atua em áreas periféricas da cidade. Sempre nas palavras de Maria do Céu Machado,

o emprego ilícito de remédios abortivos, facilmente adquiridos no mercado negro, sendo fáceis de comprar, especialmente nos meios africanos e brasileiros, é uma das causas do nascimento de bebés prematuros e com problemas de saúde. Especialmente considerando que nas mulheres destes grupos imigrantes são frequentes as gravidezes não vigiadas, ao ponto de muitas mulheres ignorarem quando ficaram grávidas. ${ }^{5}$

Uma das principais conclusões do estudo Iguais ou diferentes? Cuidados de saúde maternoinfantil a uma população de imigrantes (Machado, 2007) é que nas comunidades imigrantes existe maior mortalidade fetal e neonatal, mais doenças durante a gravidez, nomeadamente infecciosas. A vulnerabilidade dos imigrantes decorre, em primeiro lugar, das características da família: desemprego, tipo de emprego, escolaridade, famílias monoparentais ou alargadas, debilidade psicossocial e económica, falta de higiene habitacional e pessoal e maior consumo de álcool (Machado et al., 2007b). O conceito de higiene, com as suas conotações de civilização, educação, responsabilidade e moralidade, torna-se nestas intervenções de saúde pública uma forma de avaliar a idoneidade dos imigrantes à cidadania. A doença, assim como a gravidez adolescente, são consideradas como resultados da falta de responsabilidade e consequência negativa de condutas desordenadas e imprudentes.

\section{Conclusão: entre humanitarismo e ortopedia moral}

O princípio de base desta pesquisa, para tentar oferecer um contributo mais útil tanto para o debate público como para o debate teórico, foi o de não tomar partido, criando as condições para compreender ambos os lados do argumento, dos técnicos de intervenção social e dos utentes. A tentativa foi de evidenciar as lógicas subjacentes aos discursos proferidos pelos interlocutores entrevistados. Como sublinha muito bem Fassin $(2005,2010)$, analisar a política da compaixão significa abordar uma questão extremamente complexa, na qual existe solidariedade e desigualdade, na base de uma 
relação sempre profundamente assimétrica. 0 governo humanitário das vidas precárias cria, pelos seus pressupostos morais, um consenso geral que desarma a crítica: a compaixão não tem inimigos. Uma análise deste tipo todavia significa apresentar as contradições intrínsecas nos discursos e programas políticos - não significa ver nestes teorias da conspiração ou do controle social. Significa analisar a construção orgânica dos projetos de apoio social e as justificações em que se baseiam - não significa duvidar das suas boas intenções. Significa estudar as explicações e atitudes dos profissionais do âmbito social num contexto histórico-político de relações de poder a variados níveis não significa denunciar qualquer tipo de incompetência ou má-fé.

A característica distintiva da vontade de cuidar de populações desfavorecidas não é de algum tipo de controle social, mas sim de outra natureza. Como nunca antes, estas populações são visadas por um complexo conjunto de políticas governamentais a vários níveis, mecanismos de autoridade, agências de assistência social, campos de expertise científica, e atores institucionais de comunidade que possuem preocupações sobrepostas de care e segurança. Esta coincidência de preocupações sociais com uma estratégia de segurança juntou-se a uma forma liberal-cosmopolita de governança global cujo objetivo essencial - mas não exclusivo - é "conduzir a conduta" de certas populações no sentido de subjetividades liberais, capacitadas, autónomas e empreendedoras, tanto dentro dos estados, nas fronteiras, e entre estados com uma crescente internacionalização das políticas de assistência social. Estas políticas espelham uma nova forma de governar populações específicas para além do Estado, com o crescimento de uma indústria de social care e agências não-governamentais profissionalizadas e privatizadas responsáveis por desenvolver e praticar programas de assistência ao nível nacional e internacional. Os casos apresentados, analisando em particular o sector da saúde, são exemplos destas novas formas de profissionalização do apoio social. $\mathrm{O}$ interessante aqui é o esbatimento das fronteiras onde o saber médico passa do ato de governar o corpo segundo uma lógica médica para governar o corpo segundo uma lógica de bem-estar social. Ou seja, o saber médico incorpora a própria racionalidade de como se governa através do social, aconselhando, prevenindo, atuando de forma médica não sobre um problema médico, mas sobre um problema social.

38 Em jeito de conclusão, mas também de disclaimer, se o assunto tanto na sua configuração histórica como nos seus desenvolvimentos é particularmente fascinante, é igualmente sensível do ponto de vista político - mais ainda no nosso tempo de crise económica. As questões do assistencialismo, da segurança social, distribuição de rendimentos ou humanitarismo são disputadas ferozmente por fações, partidos, governos de esquerda e direita por diferentes motivos e, mais uma vez, como substituição de outros tipos de debates essenciais. Alguns empenharam-se em desconstruir o programa "arrogante" ou "colonialista" do desenvolvimento; outros empenharam-se em defender a nobreza em condições difíceis dos assistentes sociais, profissionais médicos ou voluntários; outros ainda empenharam-se em encontrar no mau funcionamento do sistema de assistência social uma justificação para fomentar a privatização do sector e cortes nos benefícios fiscais. Este tipo de pesquisa pode e deve afastar-se do debate das condições estritamente políticas do Estado do Bem-Estar. Pode e deve, ao invés, promover uma dupla rutura: uma que, em vez de dar por garantidas as classificações de vulnerabilidade e risco, se dedique a analisar as bases históricas que sustenta este Will to Care, este poder moral imanente do fazer o Bem; e outro que 
pretende inquirir as mudanças paradigmáticas profundas de como se concebe a distinção entre seres humanos e a cada vez mais difundida e penetrante forma de os governar em todas as dimensões das suas vidas.

\section{BIBLIOGRAFIA}

ALARCÃO, V. et al. (2008), «Utilização de métodos contraceptivos pelas mulheres imigrantes das comunidades de origem africana e brasileira em Portugal», póster apresentado no VI Congresso de Epidemiologia, Porto, 23 e 24/10/2008.

BECKER, H. (1963), Outsiders: studies in the sociology of deviance, Nova Iorque, The Free Press.

COWEN, M. e R. Shenton (1996), Doctrines of Development, Londres e Nova Iorque, Routledge.

DEAN, M. (1999), Governmentality: Power and Rule in Modern Society, Londres, Sage.

DIAS, S. et al. (2009), Saúde sexual e reprodutiva de mulheres imigrantes africanas e brasileiras, ACIDI, OI 32.

DUFFIELD, M. (2007), Development, Security and Unending War, Cambridge, Polity.

FASSIN, D. (2005), “Compassion and Repression: The Moral Economy of Immigration Policies in France", Cultural Anthropology, 20 (3), pp. 362-387.

FASSIN, D. (2010), La raison humanitaire. Une histoire morale du temps présent, Paris, Hautes Études Gallimard - Seuil.

FONSECA, M.L. et al. (2009), Mighealthnet. Relatório sobre o Estado da Arte em Portugal, Centro de Estudos Geográficos, Instituto de Geografia e Ordenamento do Território (IGOT-UL).

INDA, J. (2006), Targeting Immigrants: Government, Technology, and Ethics, Malden, MA e Oxford, Blackwell Publishing.

MACHADO, M. (2007), Iguais ou diferentes? Cuidados de saúde materno-infantil a uma população de imigrantes, Editor Laboratórios Bial.

MACHADO M. et al. (2007), «Cuidados de saúde materna e infantil a uma população de imigrantes», in S. DIAS (org.), Revista Migrações - Número Temático. Imigração e Saúde, Setembro 2007, n.ำ 1, Lisboa: ACIDI, pp. 103-127.

MEHTA, U. (1999), Liberalism and Empire, Chicago, University of Chicago Press.

ROCHA, C. et al. (2010), “Conhecimentos sobre o uso de contraceptivos e prevenção de DST: a percepção de mulheres imigrantes”, Cad. Saúde Pública, vol. 26, n. ํ5, pp. 1003-1012.

ROSE, N. e P. Miller (2008), Governing the Present, Cambridge, Polity.

\section{NOTAS}

1. Este tipo de questionamento enquadra-se numa crescente linha de investigação preocupada com as formas de governo no liberalismo avançado, suscitada por um conjunto de temas 
desenvolvidos por Michel Foucault nas Léctures do Collège de France, nomeadamente os de "governamentalidade" (1977-78) e "biopolítica" (1978-79). Para importantes leituras do campo, conceitos e implicações teóricas, cf. por exemplo Rose e Miller (2008) e Dean (1999).

2. Discurso de George W. Bush de 22 de Março de 2002 na United Nations Financing for Development Conference.

3. Alarcão et al., 2008; Dias et al., 2009; Fonseca et al., 2009; Rocha et al., 2010.

4. Fonte: Público, 30.07.2010.

5. Fonte: Público, 10.09.2004.

\section{RESUMOS}

No contexto recente da União Europeia os assuntos relacionados com a imigração tomaram uma importância fundamental na atividade governamental, criando a necessidade de estudar, categorizar e monitorizar as populações migrantes, assim como promover a sua integração. Este artigo explora a ideia de que, entrelaçados com retóricas como a da "pobreza" e a "vulnerabilidade", os programas sociais de cariz assistencialista que tomam por objeto as populações migrantes desfavorecidas equacionam o objetivo da redução da pobreza com o objetivo de orientar a sua conduta no sentido de hábitos e projetos de vida mais responsáveis e saudáveis. Este artigo irá também explorar, centrando-se no contexto português, como estas intervenções são inerentemente racializadas, constituindo um tipo de etnopolítica dirigida a populações imigrantes, concebidas como necessitadas e desfavorecidas - não apenas de recursos económicos mas também de recursos de cidadania. Partindo de um conjunto de debates sobre o governo do corpo e da saúde no liberalismo avançado, o artigo sugere tópicos para uma nova agenda de investigação sobre pobreza, risco, imigração e o sector da saúde pública.

In the recent context of the European Union governmental activity, immigration-related issues became of pivotal importance, raising the need to study, categorize and monitorize immigrant populations, as well as to promote their integration. This paper explores the idea that, interwoven with rethorics such as "poverty" and "vulnerability", social care programs targeting deprived migrant populations equate reducing poverty with guiding their conduct towards more responsible, healthier habits and life projects. This paper will also argue, focusing on the Portuguese context, how these interventions are inherently racialized, constituting a kind of ethnopolitics targeting migrant populations conceived as needy and deprived - not only of economical resources but also of citizenship resources. Building upon a set of debates on governing the body and health under advanced liberalism, this paper suggests ideas towards a new research agenda on poverty, risk, immigration, and the public healthcare sector.

\section{ÍNDICE}

Palavras-chave: imigração, pobreza, assistencialismo, saúde

Keywords: immigration, poverty, social care, health 


\section{AUTORES}

\section{CHIARA PUSSETTI}

Investigadora Sénior do CRIA e Professora Auxiliar Convidada do ISCTE/IUL

(chiaragemma.pussetti@gmail.com)

\section{VITOR BARROS}

Doutorando em Spanish, Portuguese \& Latin American Studies no King's College (Londres)

(dawidbar@googlemail.com) 